\title{
Feminine Intrastructures in a Men-made City
}

\section{Anna-Maria Walter and Anna Grieser}

In Gilgit city, capital of Pakistan's northernmost region Gilgit-Baltistan, women are largely absent from public space. The streets are filled with men: male soldiers patrol military checkpoints, ${ }^{1}$ men steer motorbikes and public transport vans through busy traffic, male shopkeepers sit among their open displays of merchandise along the arterial roads. In a society organized along purdah lines - gender segregation that maintains the seclusion of women - running errands outside of the home falls into the area of the man's responsibility. Consequently, men dominate the city center's fruit and vegetable stalls, electronics and crockery shops, restaurants, and banks - as shopkeepers and staff as well as customers.

Women rarely venture into masculine public spaces such as markets, and when they do, they are often accompanied by a male chaperone, are appropriately veiled, and move quickly into side alleys so as to spend as little time as possible 'out of place', limiting their interactions with men who are not family members. Women's spaces are the home and their neighborhoods, where they live among extended kin and move relatively freely since unknown men avoid these semi-private backstreets (Gratz 2006). Spatial seclusion, the "symbolic shelter" (Papanek 1982: 35) of women's large veils, 


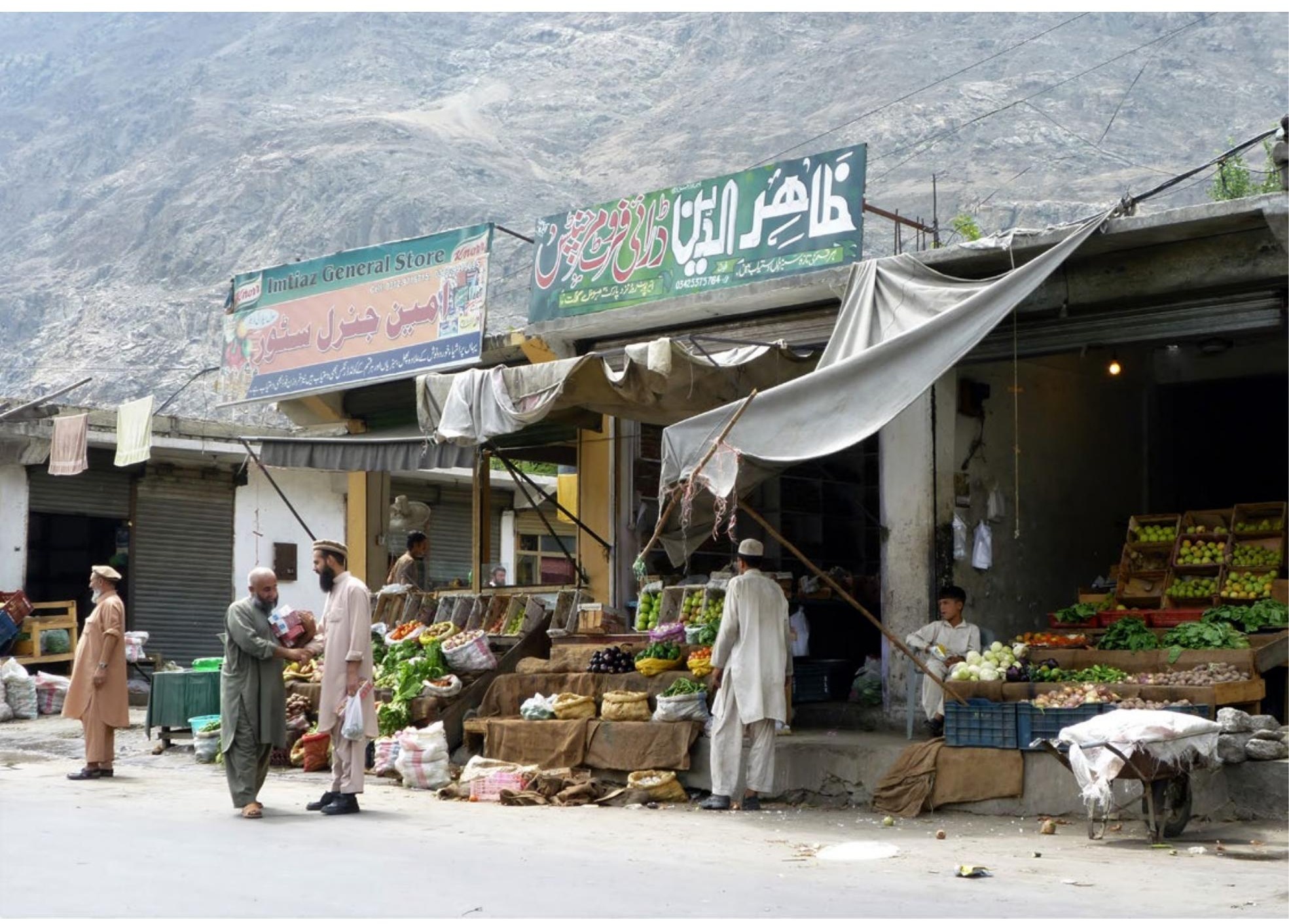

and embodied reserve (Walter 2016) safeguard them against threats from the outside world, be they real masculinist transgressions or mutual surveillance of one's family's reputation. Due to large-scale migration from the region's relatively remote valleys to the urban areas of Gilgit in the last few decades, ${ }^{2}$ its population now is ethnically, linguistically, and religiously very heterogeneous - creating an atmosphere prone to mistrust and gossip that scrutinizes women's movement through the cityscape (Grieser 2016). Accordingly, public transport and restaurants provide spaces designated for women, and only a few schools teach students in a co-educational setting.

() Click here to open an audio file recorded in one of Gilgit's neighborhoods. Recording: Anna-Maria Walter, 2014.

With a more diverse and dense population, urban planning and private architecture in Gilgit have been shaped by increasingly gendered spatial segregation and the seclusion of women. Residential buildings are designed to follow purdah imperatives: windows
Gilgit's markets are dominated by men. Photo: Claudia Stadler, 2013. 
do not face onto the street, walkways, or neighboring homes; high walls cloister houses and courtyards from the outside; newly built houses always include a separate guest room in order to keep visiting men out of the main home. Yet, however strict attempts at separation might seem, they are only necessary because full segregation along gendered lines is simply not possible - women and men's lives intersect on multiple levels and are especially deeply entangled at home.

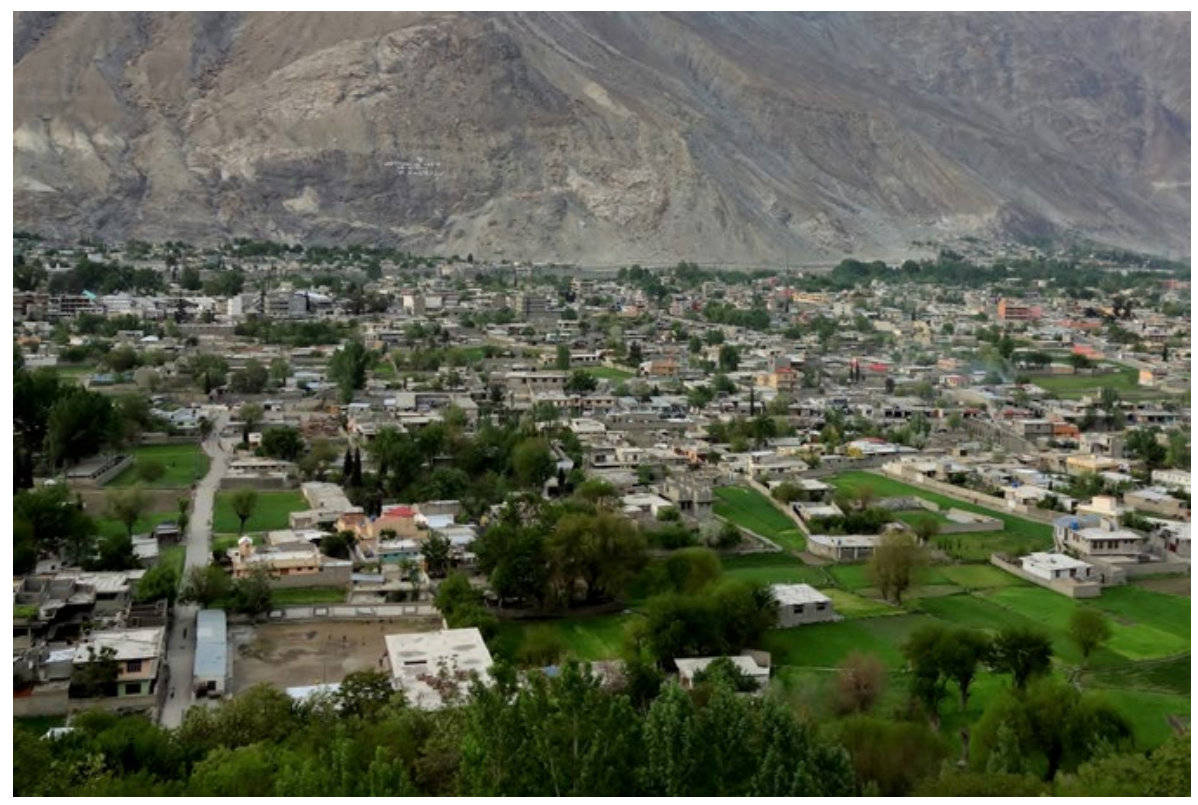

Drawing on insights taken from 2011 to today from small neighborhood shops run by women, we reveal how women creatively use the spaces that are accessible to them in order to address their needs. We argue that while women have no direct effect on urban planning, architectural design, or built infrastructure, they subvert the masculinist city from within, creating an intrastructure that is characterized by the appropriation of existing architectural elements.

Although women's participation in Pakistan's formal job sector has gradually increased over recent decades, gendered city spaces, infrastructures, and expectations continue to make the securing of paid employment a challenge for women in Gilgit-Baltistan, as is the case throughout the country (Mirza 2002; Ahmad 2012). In Gilgit, women have therefore found a way to engage in economic activity on their own terms, both as entrepreneurs as well as customers: in the private space of the home they establish commercial 'ladies' shops' and 'beauty parlors' as they are called using these English words. The first ladies' shop in the city opened in a private house around 1960 (Gratz 1998). Over time, a semi-public shopping scene complementary to the male-dominated public bazaar has emerged in Gilgit's residential areas, all run by women for women. The majority of ladies' shops operate inconspicuously behind high walls and closed gates; there might only be a faded signboard above a door to indicate the entrance. 


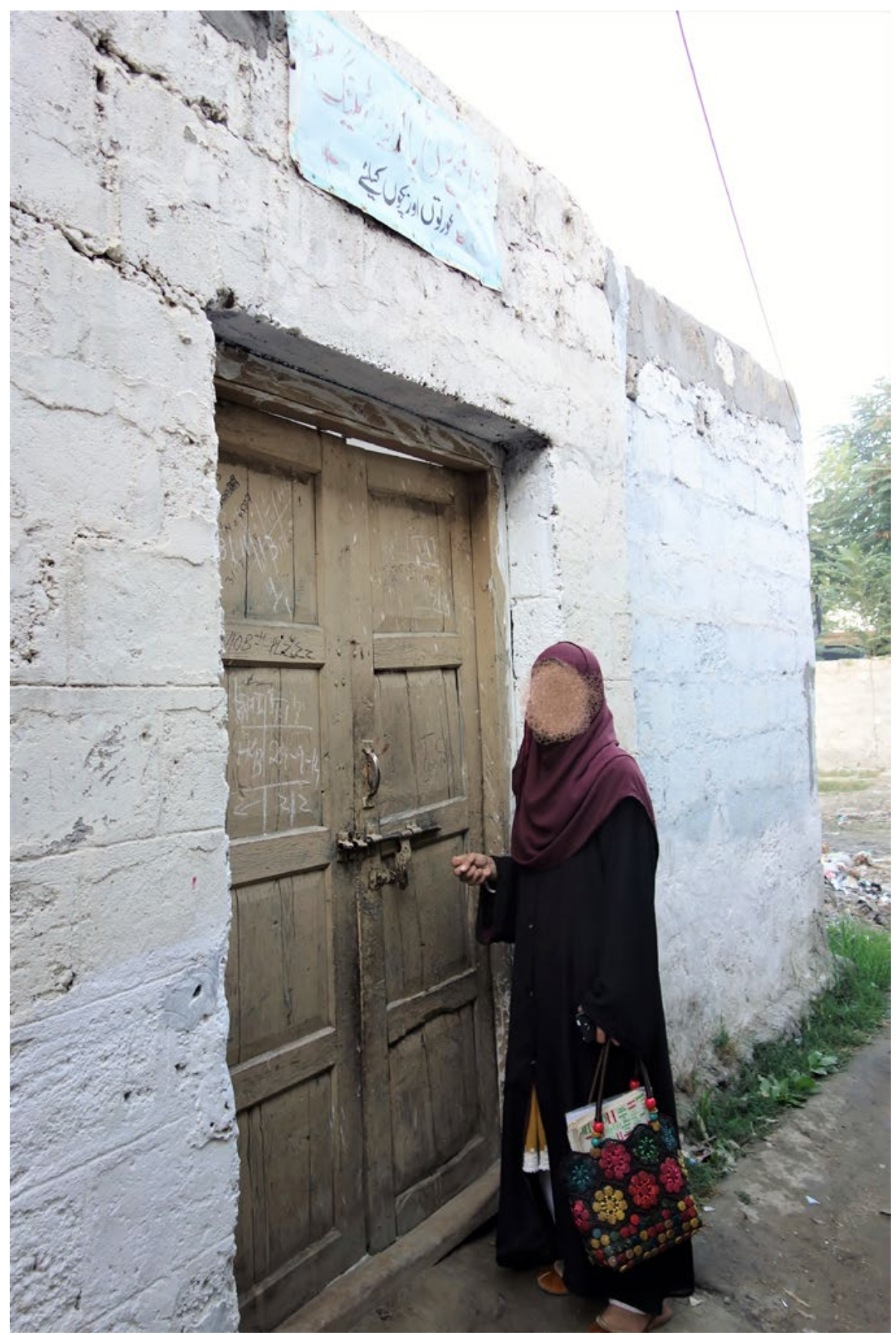

A young woman

knocking at the door of a neighborhood beauty parlor.

Photo: Anna-Maria Walter 2014

But step through the door and an entirely different space opens up, one that is very much an inverse of the public sphere. Here women linger, chatting and laughing in a relaxed atmosphere, unconcerned about loose dupattas ('veils', in Urdu) and exposed skin, their clothes intensely colored and contrasting with the dusty grey of the general cityscape. As Banu, ${ }^{3}$ a shop-owner in her mid-forties explained, the fact that there are no men in the ladies' shops makes her customers feel at ease. A married woman in her late twenties chimed in: "There is no rush in the ladies' shops, you can do your 
shopping in peace (skoon)." Women take their time browsing embroidered housewares, women's and children's wardrobes, lingerie, toiletries, and other household or women's products, waiting their turn to get their hair colored or eyebrows shaped.

In many ways, Gilgit's ladies' shops and beauty parlors conform to properties generally assigned to infrastructure: they are embedded, often invisible. As infrastructures are ideally entrenched, hidden behind walls or under streets, they are only noticed when they fail and have to be exposed for repair. They mediate and shape social practice almost unnoticeably, from inside out (Gupta 2015; Niewöhner 2015). But ladies' shops' invisibility is not an outcome of careful planning; instead, women use existing architecture and creatively reconfigure the interior of their family homes to carve out space for themselves. Converting a private room into a business requires only few changes - fresh paint, perhaps a partitioning curtain for the front door, and simple wooden shelves. We therefore understand these improvised places as intrastructures that challenge men's city planning from within - a way of appropriating architectural spaces after they have been constructed; a semi-public network of feminine hotspots within the masculine cityscape.

Although women reproduce the gendered social order by creating culturally acceptable and spatially discrete business opportunities, they simultaneously contest gendered exclusions and constraints by developing new opportunities for women's earning, consumption, leisure, and engagement with other women. Businesswomen who make places of comfort for themselves and each other become more financially independent - such as Banu, whose main motive for opening a ladies' shop was her husband's continuously precarious income but also her wish to engage with women other than close relatives. Nevertheless, women depend on the support of male kin, be it father, husband, or father-in-law, who need to approve of the reassignment of the family's space - as well as the woman's time - for the business. After all, having part of their family home turned into a semi-public space for kin and non-kin women, it is the men who must respect purdah rules in their own house.

As indicated above, spatial boundaries between private and public, feminine and masculine spaces, are not always as clear-cut as theoretical conceptions of purdah might suggest. The architecture of Gilgit's houses with their high walls, for example, implies that nothing from the inside penetrates outside, or vice versa. But loud outbursts of laughter or excited chatter frequently travel through the air. Gossip from the women's circles will surely make its way to men's ears. And when the sudden and immediate sensation of the loud metallic sound that is the prayer call (azan) echoes through Gilgit, it reminds women of their obligations to cover their heads or to hurry home. Gendered lifeworlds are more porous than a first glance suggests.

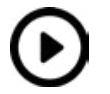

Click here for an audio demonstration of the publicly disseminated masculine call to prayer, in contrast to female domestic activity. Recording: Anna-Maria Walter, 2014.

The next day, once again more female customers will come and bring the inconspicuous and improvised network of ladies' shops to life. Less than thinking of architecture as a way of serving people's needs, our observations serve to raise awareness of 


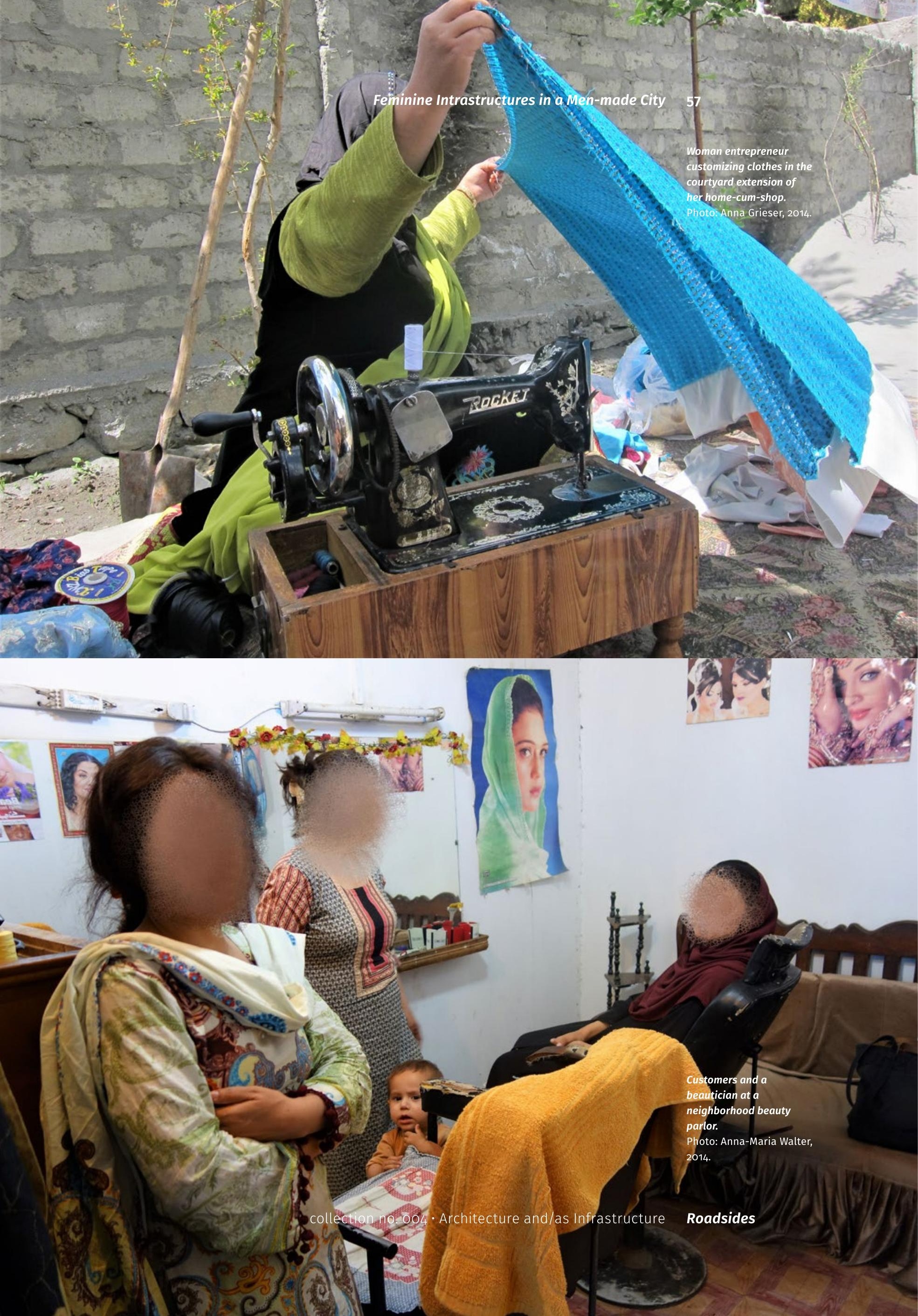


women's subversive and dynamic potential to appropriate places designed and made by men. In this way, women disrupt and recuperate spatial exclusions. By adhering to expectations about permissible movements and interactions, they manage to acquire the support, or at least silent consent, of men in order to create their own opportunities for economic and leisure activities. When converting part of their private family home into the semi-public space of a beauty parlor or ladies' shop, women's claim to partake in and make a contribution to public life materializes in this ingenious way of utilizing existing structures in a fundamentally different manner than they were meant to be used by the men who made them.

\section{Notes:}

${ }^{1}$ Owing to the ongoing Kashmir dispute between Pakistan and India, in which GilgitBaltistan is implicated, the region is highly militarized and continually patrolled by army personnel.

${ }^{2}$ Gilgit city has grown from roughly 5,000 inhabitants at the beginning of the twentieth century to 58,000 in 1998 and then roughly 120,000 people in Gilgit and its suburbs at the time of the last census in 2017.

${ }^{3}$ All interlocutors (names and faces) are anonymized to comply with purdah guidelines for a public audience.

\section{References:}

Ahmad, Sadaf. 2012. "AASHA's Approach to Instituting Sexual Harassment Legislation in Pakistan." In New South Asian Feminisms: Paradoxes and Possibilities, edited by Srila Roy, 44-65. London: Zed Books.

Gratz, Katrin. 1998. “Walking on Women's Paths in Gilgit: Gendered Space, Boundaries, and Boundary Crossing." In Karakorum - Hindukush - Himalaya: Dynamics of Change. Part II, edited by Irmtraud Stellrecht, 489-508. Köln: Köppe.

Gratz, Katrin. 2006. Verwandtschaft, Geschlecht und Raum: Aspekte weiblicher Lebenswelt in Gilgit/Nordpakistan. Köln: Köppe.

Grieser, Anna. 2016. "When the Power Relationship is not in Favour of the Anthropologist: Reflections on Fieldwork in Gilgit-Baltistan." Zeitschrift für Ethnologie 141 (2): 177-196.

Gupta, Akhil. 2015. "An Anthropology of Electricity from the Global South." Cultural Anthropology 30 (4): 555-568. DOI: https://doi.org/10.14506/ca30.4.04

Mirza, Jasmin. 2002. Between Chaddor and the Market: Female Office Workers in Lahore. Oxford, New York: Oxford University Press. 
Niewöhner, Jörg. 2015. "Anthropology of Infrastructures of Society." In International Encyclopedia of the Social \& Behavioral Sciences, edited by James D. Wright, 119-125. Oxford: Elsevier.

Papanek, Hanna. 1982. "Purdah: Separate Worlds and Symbolic Shelter." In Separate Worlds: Studies of Purdah in South Asia, edited by Hanna Papanek and Gail Minault, 3-53. Delhi: Chanakya Publications.

Walter, Anna-Maria. 2016. “Between 'pardah' and Sexuality: Double Embodiment of 'sharm' in Gilgit-Baltistan." Rural Society 25 (2): 170-183. DOI: https://doi.org/10.1080 $\not 10371656.2016 .1194328$

\section{Acknowledgments:}

We thank the editors and reviewers for their thorough reading of the manuscript and their valuable suggestions, which were very helpful in improving this article.

Cite as: Walter, Anna-Maria and Anna Grieser. 2020. "Feminine Intrastructures in a Menmade City." Roadsides 4: 52-60. DOI: https://doi.org/10.26034/roadsides-202000407 


\section{Authors:}

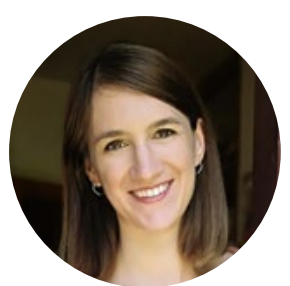

Anna-Maria Walter has worked on gender relations, mobile phones, and changing ideas of love and marriage in the area of Gilgit for almost a decade. Her monograph Intimate Connections will be published in Rutger's Politics of Marriage and Gender Series in 2021. She is a fellow at the University of Exeter and serves as part-time lecturer at the Institute of Social and Cultural Anthropology at LMU Munich. Her new research projects cover arenas of feminist partaking in pleasure and spirituality in high-altitude spaces as well as conceptions of the self through social media use.

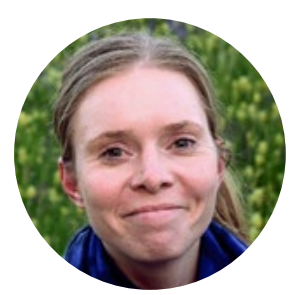

Anna Grieser is currently a Postdoctoral Fellow at the Centre for Excellence in Women and Child Health, Aga Khan University. Having worked with different universities as well as the Aga Khan Rural Support Programme Pakistan, she is interested in postmodern and autoethnographic approaches to ethnography, natural resources management, social mobility, ageing, as well as questions of 'development'. Her doctoral dissertation on the waterscape of Gilgit was granted the 2017 Award of the Faculty for the Study of Culture of the LMU Munich. 
Roadsides is an open access journal designated to be a forum devoted to exploring the social, cultural and political life of infrastructure.

\section{Editorial Team:}

Julie Chu (University of Chicago)

Tina Harris (University of Amsterdam)

Agnieszka Joniak-Lüthi (University of Zurich)

Madlen Kobi (Academy of Architecture, Mendrisio)

Nadine Plachta (University of Colorado Boulder)

Galen Murton (James Madison University, Harrisonburg)

Matthäus Rest (Max-Planck-Institute for the Science of Human History, Jena)

Alessandro Rippa (LMU Munich and Tallinn University)

Martin Saxer (LMU Munich)

Christina Schwenkel (University of California, Riverside)

Max D. Woodworth (The Ohio State University)

Collection no. 004 was edited by: Madlen Kobi and Nadine Plachta

Managing editor: Agnieszka Joniak-Lüthi

Copyediting: David Hawkins

Layout: Chantal Hinni and Antoni Kwiatkowski

\section{ISSN 2624-9081}

\section{Creative Commons License}

This work is licensed under a Creative Commons Attribution-NonCommercial-ShareAlike 4.0 International License.

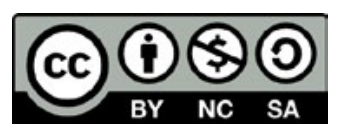

